\title{
Elite y poder en Tucumán, Argentina, segunda mitad del siglo XIX. Problemas y propuestas ${ }^{*}$
}

\author{
María Celia Bravo \\ Daniel Campi \\ CONICET-UNIVERSIDAD NACIONAL DE TUCUMÁN
}

El artículo trata del sistema de poder en Tucumán a fines del siglo XIX, planteando una serie de cuestiones que hasta hoy no han merecido la atención de los historiadores. Se propone combinar dos niveles de análisis: el de la formación social y el de las prácticas políticas de la elite, la que evolucionó hasta constituirse en un poderoso empresariado azucarero de preeminencia indiscutida en la provincia y con gran proyección en el escenario nacional.

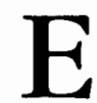

1 periodo comprendido entre 1852 y 1880 se conoce en la historiografía argentina como el de "la organización nacional". Aunque los 30 años que separan al derrocamiento de Juan Manuel de Rosas en Caseros de la llegada de Julio A. Roca a la presidencia no dejaron de ser años

\footnotetext{
* Una primera versión de este trabajo se presentó en el Simposio Poder y grupos sociales. IV Jornadas sobre grupos sociales dominantes regionales. México y Argentina, organizado por el Instituto Nacional de Antropologia e Historia en la ciudad de México, 20-22 de junio de 1994. Se agradecen los comentarios que en esa oportunidad formuló Marta Bonaudo.
}

de guerra civil y hasta de secesión (como la protagonizada por la provincia de Buenos Aires entre 1853 y 1861), en los que muy frecuentemente el poder de las armas prevaleció frente al derecho, es indudable que en ellos el Estado central fue afianzándose progresivamente, a la vez que se consolidaba un orden legal sustentado en la Constitución jurada en Santa Fe en 1853.

Más allá de las diversas interpretaciones que sobre sucesos y actores formularon los historiadores, hay consenso de que en tal periodo el poder central fue sometiendo a los particularismos provinciales, y que el respeto 


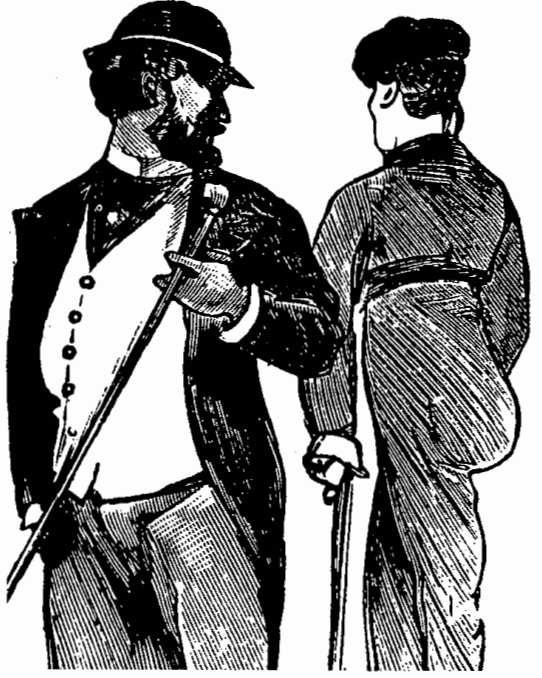

a las normas constitucionales terminó imponiéndose como fundamento del poder legítimo. El año clave y decisivo de este proceso será 1880. En él, en el postrer episodio de la larga contienda civil rioplatense, fue sometida la última resistencia localista, la de Buenos Aires, y el Estado central conquistó definitivamente el monopolio de la violencia legítima y se resolvió la añeja "cuestión capital" federalizando la ciudad-puerto.

Hay consenso también en la historiografía en que en la coalición triunfante del 80 tuvo gran protagonismo un conjunto de elites ${ }^{1}$ de las provin-

\footnotetext{
'Hemos optado por el término "elite" (frente a las categorías más problemáticas y restringi-
}

cias interiores, entre las que se destacó la tucumana, razón por la cual desde entonces fue uno de los elementos constitutivos del bloque de poder hasta la democratización política que sobrevino en la década de 1910.

Por esta razón adquiere relevancia el estudio de las bases y condiciones locales que le posibilitaron proyectarse con fuerza en la escena política nacional. No obstante ello, las aproximaciones que hasta hoy se han realizado sobre el tema son parciales e insatisfactorias. Considerando su complejidad y la inexistencia de investigaciones de base sobre las cuales arribar a conclusiones suficientemente fundadas sobre una serie de cuestiones todavía irresueltas, el objetivo del presente trabajo se orientará, sobre todo, a plantearlas y a explorar posibles soluciones a los interrogantes pendientes.

Aunque los problemas que se examinan son característicos de toda la segunda mitad del siglo XIX, nuestro análisis se detendrá en 1887 . La revolución "juarista"2 de ese año, como el primer levantamiento armado de la Unión Cívica Radical, acaecido en 1893,

das de "clase dominante" o "dirigente"), pues el mismo nos permite incluir de un modo amplio al conjunto de individuos, familias, sectores propietarios, etc., en los que confluyen prestigio social, riqueza y poder. En el caso tucumano de la segunda mitad del siglo XIX nos referimos a un grupo de familias que controlaron de un modo más o menos exclusivo la gobernación, la legislatura y el aparato administrativo provincial.

${ }^{2}$ En 1887 la facción "juarista" (así se llamaba a los partidarios del presidente Miguel Juárez. Celman, 1886-1890) derrocó por las armas al gobernador Juan Posse con el desembozado apoyo de la administración nacional. 
incorporan a la cuestión circunstancias cuyo tratamiento no está contemplado en los objetivos de este trabajo.

\section{ESTADO DE LA CUESTIÓN Y PROBLEMAS}

La visión más difundida respecto a la relación entre elite, Estado y poder en Tucumán en la segunda mitad del siglo XIX presenta a una cerrada oligarquía local detentando los cargos de gobierno de manera exclusiva y excluyente, cuyos miembros -propietarios de ingenios y latifundios azucareros vinculados entre sí por sólidos lazos de parentesco y conexiones empresariassometían al "pueblo" (asalariados, campesinos, pequeños comerciantes) a un rígido control político a través de redes clientelares, extorsión económica $y^{*}$ el uso directo de la fuerza.

Esta representación del sistema de poder -que habría perdurado hasta la puesta en vigencia del sufragio universal masculino obligatorio, sancionado por ley en 1912- fue forjada por la nueva cultura política promovida por los triunfos electorales de la Unión Cívica Radical en 1916 y 1917 a nivel nacional y provincial, respectivamente. Este movimiento, a pesar de incluir en sus filas a prominentes representantes de la elite azucarera, al redefinir la noción de ciudadanía en un registro más amplio, que garantizaba el acceso y ejercicio de los derechos políticos a todos los varones adultos, formuló una visión en la que se proponía como una alternativa democrática y "reparadora" frente a la imagen de ilegalidad y exclusivismo que atribuía al "antiguo régimen".

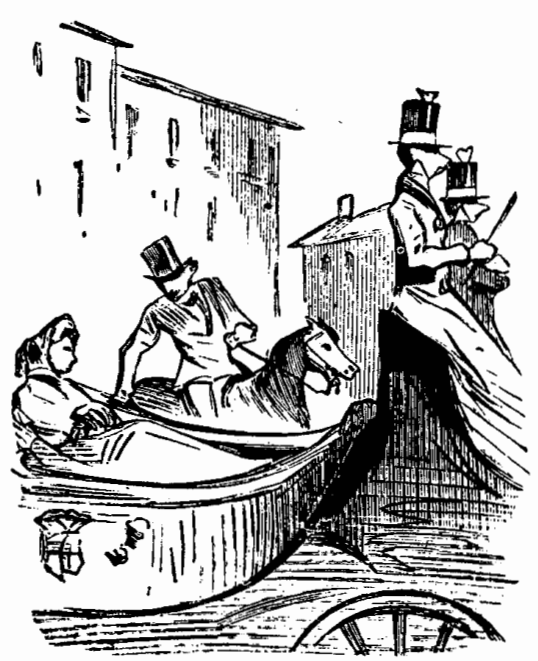

En 1917 el primer gobernador radical, Juan Bautista Bascary, describió en un mensaje a la legislatura provincial el sistema político anterior a la Ley Sáenz Peña:

Cuando ascendí al gobierno, la situación de Tucumán presentaba, quizá, como en ninguna otra parte, las características expuestas en el orden nacional. El derecho a gobernar no había descansado jamás en el electorado. Los legisladores eran designados en cónclaves familiares y por transacciones de equilibrios entre intereses de círculos distanciados del pueblo y en pugna con los sentimientos populares. El apellido, el vínculo financiero y la dependencia económica eran los determinantes de la 
actuación política dentro del oficialismo. $^{3}$

Posteriormente, al reivindicar los contenidos democráticos y antioligár. quicos del radicalismo yrigoyenista, ${ }^{4}$ el peronismo se apropiaría de esta visión, pero le conferiría otros alcances al vincular los derechos políticos con demandas de reparación social. Con base en este nuevo molde, un historiador local, Manuel García Soriano, desarrollaría la cuestión en varios artículos -elaborados a fines de los cincuenta y principios de los sesenta- referidos a la legislación laboral y al sistema electoral en Tucumán durante el siglo XIX. Para este autor, el predominio social de la elite tucumana se aseguró después de Caseros con la exclusión de "criados", "domésticos" y "jornaleros" del sistema político y con la aplicación de las leyes contra la vagancia y de la papeleta de conchabo (una "legislación del trabajo de carácter francamente esclavista, con castigos, cepos y prisiones, para someter a las masas campesinas y destruir al partido federal"). De ese modo se habría cimentado "el predominio en la dirección política del estado a las minorías cultas, constituidas

\footnotetext{
${ }^{3}$ Páez, Tucumán, 1984, p. 70. Tal imagen no desentona con las que formularian luego historiadores de diversa filiación político-ideológica sobre los mecanismos de dominación vigentes a escala nacional durante el "periodo conservador", 1880-1916.

"Se llamaban "yrigoyenistas" las tendencias de la UCR que reivindicaban la intransigencia con la que el caudillo radical Hipólito Yrigoyen (presidente entre 1916-1922 y 1928-1930) enfrentó a las fuerzas conservadoras, en contraposición con los sectores "antipersonalistas", propensos a conciliar y a coligarse con ellas.
}

ya en verdaderas oligarquías", limitándose la política tucumana a "simples rencillas domésticas entre las poderosas y grandes familias locales por la conquista del gobierno y el reparto de los cargos legislativos". 5

La visión de García Soriano mistificaba, sin duda, una instancia de "democracia inorgánica" en el pasado federal que no parece tener sustento. En 1834, la constitución propuesta por el gobernador federal Alejandro Heredia suspendía los derechos de ciudadanía a quienes no sabían leer ni escribir, con lo cual se excluía de las asambleas electorales a la abrumadora mayoría de los varones adultos, ${ }^{6}$ exclusión idéntica -en la práctica - a la de la ley electoral de 1826, votada en pleno periodo unitario. En este punto acordaban tanto "unitarios" como "federales" porque, más allá de la gran movilización de los sectores sociales subalternos durante las campañas de la independencia y las guerras civiles, éstos eran incapaces de formular ninguna alternativa de poder independiente de las elites.

Esta sesgada imagen del pasado federal se correspondía con una visión estática y sin matices del periodo "liberal" que se inicia con la caída de Juan Manuel de Rosas. Por un lado, las op-

${ }^{5}$ García, "Asalariado", 1961, pp. 61 y 72.

"Sosa, Historia, 1945, p. 61. El artículo 15 de este proyecto definía las condiciones exigidas para el cargo de representante (diputado): "ciudadanía natural en ejercicio, o legal adquirida dos años antes de su nombramiento; 22 años cumplidos; un capital de 2000 pesos o, en su defecto, profesión, arte u oficio útil que le produzca un modo de vivir honesto o independiente", ibid., pp. 66-67. 
ciones políticas en Tucumán -en una mirada que abarca casi todo el siglohabrían sido sólo reflejos locales de una gran confrontación nacional signada por el conflicto entre el Partido Federal y el Partido Unitario, conflicto que se proyectaba mecánicamente al campo social en el marco de un persistente enfrentamiento entre la elite y las masas populares. Asimismo, las disputas políticas entre los diversos sectores de la elite fueron consideradas "simples rencillas domésticas", y la hegemonía demostrada por las familias que accedieron a posiciones importantes en el poder local eran concebidas como una simple prolongación natural de su dominio económico. Por último, la cuestión bajo estudio no presenta durante toda la segunda mitad del siglo XIX ninguna modificación sustancial: "Ia oligarquía" no habría sufrido alteraciones con los avatares económicos, sociales y políticos del periodo; el sistema de dominación no se habría adaptado frente a nuevas coyunturas, y las grandes transformaciones económicas y sociales que experimentó la provincia en dicho lapso tampoco las impusieron. Del mismo modo, es ésta una imagen ahistórica de los sectores subalternos, que invariablemente son presentados como sujetos pasivos, incapaces de modificar mínimamente sus condiciones de existencia. ${ }^{7}$

${ }^{7}$ Aunque la de García Soriano es la única formulación más o menos sistemática sobre el sistema de poder en la historiografia tucumana, otros autores han contemplado, de un modo u otro, esta problemática. Al respecto no deja de ser sorprendente la coincidencia con García Soriano, en más de un aspecto, de autores que se inscriben en tradiciones políticas e historio-
Aquí están planteadas, a nuestro entender, algunas de las cuestiones claves si se pretende estudiar el sistema de poder en toda su complejidad, el que debe contemplar, como un todo, las estrategias y los mecanismos de dominación que se ejercen en todos los planos sobre el "complejo constituido por los hombres y las cosas". ${ }^{8}$ En esa perspectiva se deberá abordar: 1) El proceso de construcción de la formación social, ahondar sobre la génesis y desarrollo de los sectores dominantes y sus mecanismos de acumulación, los ajustes y adaptaciones que exige la creciente vinculación de la región a la economía pampeana agroexportadora y

gráficas muy diferentes, tales son los casos de Páez de la Torre y Rosenzvaig. El "primero, que presenta a los prohombres de la elite como exclusivos actores históricos que construyen el Tucumán moderno, exalta como fundamento del poder que detentaban algunas familias -junto con la posesión de estancias e ingenios y eficaces redes parentales- sus "innatas condiciones para mandar y sobresalir" (Páez, "Revolución", 1978, p. 32). El segundo, a su vez, afirma: "Si en Santiago o en Salta la elite siguió siendo apellido, educación e bistoria política, en Tucumán significaba propiedad de ingenio. Un desconocido -un extranjero- que adquiriese un ingenio, compraba al mismo tiempo apellido, educación y por supuesto decisión política" (Rosenzvaig, Historia, 1987, p. 148; cursivas en el original). Diferente es el caso de Donna Guy, quien en su magnífica tesis "Política azucarera argentina. Tucumán y la generación del $80^{\text {" }}$ muestra un panorama muy complejo del tema, articulando a partir de lo político -sin simplificaciones ni mecanicismos- los intereses económicos, los lazos familiares, la cuestión social, etc. Guy, Política, 1981. Esta última obra sigue siendo punto de referencia indispensable para cualquier aproximación a la historia tucumana y del norte argentino de fines del siglo XIX.

${ }^{8}$ La expresión pertenece a Foucault. Foucault, "Gubernamentabilidad", 1991, p. 15. 
su inserción en el mercado nacional en formación; 2) el ámbito de lo político, en dos planos: $a$ ) el contexto en el que se inserta la situación provincial, el de la construcción del Estado-nación (en este nivel se ubican las tensiones no resueltas entre provincias interiores y Buenos Aires, el papel del ejército nacional en el proceso, la decadencia del mitrismo y el ascenso roquista, ${ }^{\text {? }}$ etc.); b) los mecanismos de la dominación política y del ejercicio del poder (redes parentales y clientelares; participación política de las clases populares; naturaleza de las luchas intestinas en el seno de la elite; prácticas electorales, etc.); 3) los medios de persuación ideológicos a través de los cuales el predominio político de la elite es aceptado y reconocido como legítimo por los sectores subalternos; 4) los instrumentos de control social, de disciplinamiento y "moralización" de los sec-

\footnotetext{
"Las denominaciones "roquismo" y "mitrismo" remiten a distintos sistemas de alianzas que, bajo la forma de facciones políticas regionalmente dispersas, articulaban a representantes del ejército y a diferentes segmentos de las elites regionales. Su diferencia central consistía en el papel y la fortaleza que se asignaba al Estado nacional. Mientras el roquismo reservaba al mismo una centralidad excluyente en el escenario político, en el cual, como garantia de go bernabilidad, debian incorporarse necesariamente el conjunto de las elites provinciales, el mitrismo -en el que el predominio del segmento más concentrado de la burguesia mercantil porteña era decisıvo- se inclinaba a conformar una estructura central menos vigorosa que no amenazara ef creciente poder que la todavía no federalizada provincia de Buenos Aires había alcanzado en ausencia de un Estado central. El enfrentamiento armado que tuvo lugar en 1880 dirimió la disputa en torno a estas distintas concepciones.
}

tores subordinados en función de optimizar la acumulación de capital, forzar la adaptación de los trabajadores a las opciones económicas y tecnológicas adoptadas por la elite y controlar o eliminar todo acto o conducta de resistencia. ${ }^{10}$

En síntesis, la exigencia es la de ahondar sobre la historicidad del proceso de conformación de la elite, de construcción de los instrumentos de dominación y de las prácticas políticas. Es probable que la imagen de las más poderosas familias propietarias de ingenios que accedieron al gobierno de la provincia a partir de 1880 , y de un modo más exclusivo entre 1905 y 1917 , contribuyó a proyectar ese estado de cosas a toda la segunda mitad del siglo xIX. Sin embargo, esa elite, gran protagonista en la construcción del Estado moderno argentino y en la exitosa inserción de las provincias norteñas en el modelo agroexportador a través de la especialización azucarera, fue también una de las "criaturas" del proceso, tal como lo planteó Halperín Donghi en relación con la poderosa clase terrateniente bonaerense en el contexto de la expansión contemporánea de la economía pampeana. ${ }^{11}$

${ }^{10}$ En este trabajo no se desarrollarán, deliberadamente, los dos últimos puntos. Uno de los autores estudia la problemática del control social a partir del análisis de las normativas y los usos sociolaborales, de los que se desprende un protagonismo de los sectores populares inadvertido hasta ahora por la historiografia. Véase Campi, "Captación", 1991; "Captación", 1993, y "Auge", 1993.

11 "La clase terrateniente sólo iba a surgir de modo lento y gradual del magma de las clases propietarias; es apenas exagerado que esa clase 
EUTE, ACUMULACIÓN DE CAPITALES Y SOCIEDAD

Como ya se ha dicho, el papel desempeñado por la elite tucumana en la construcción del Estado-nación fue destacado casi de forma unánime por los historiadores argentinos. Halperín Donghi caracteriza como "desproporcionada" la presencia de las "muy poco prósperas elites del interior" en "el personal político, administrativo y militar del nuevo Estado". ${ }^{12}$ Ansaldi, a su vez, encuentra el fundamento de ese protagonismo en un "pacto oligárquico" que, bajo la dirección de Buenos Aires, habría sellado los intereses de las clases dominantes del interior con las del litoral..$^{13}$ Jorge Sábato, por su parte, define tal acuerdo con mayor precisión y propiedad:

Una mayor preponderancia dentro del Estado y, en particular, el control del ejército nacional, eran las cartas que podían jugar los grupos del interior para poder pactar con los del litoral un acuerdo mediante el cual compartiesen los frutos de la nueva sociedad que se estaba conformando. En este sentido puede decirse que, en 1880 , algunas fracciones del interior triunfarán sobre las porteñas y el presidente Roca sabrá manejar hábilmente la situación para que el acuerdo subsiguiente sea aceptable por todos. ${ }^{14}$

era más que la beneficiaria, la criatura de la expansión exportadora"; Halperín, "Clase", 1992, p. 11.

12 Ibid., p. 13.

${ }^{13}$ Ansaldi, "Notas", 1985, pp. 551-552; "Frivola", 1991-1992, pp. 45-46.

${ }^{14}$ Sábato, Clase, 1988, p. 166.
Sin embargo, se ha estudiado insuficientemente la génesis de esa "oligarquía" o "burguesía" azucarera, cuya influencia rebasó con holgura, como se reconoce, los límites regionales. Hasta el presente se han formulado aproximaciones sobre el tema, desarrollando -ante todo- hipótesis de trabajo, algunas muy consistentes, como las de Giménez Zapiola y Balán. ${ }^{15}$ Faltan, sin duda, trabajos sistemáticos de base que ahonden sobre los diversos y complejos problemas considerados, particularmente dos de ellos: el de las estrategias de acumulación de capitales en el ámbito regional que habrían permitido a un segmento de comerciantes de San Miguel de Tucumán acceder al estadio industrial y convertirse en el poderoso empresariado azucarero de fines de siglo $\mathrm{xIX}$, propietario de modernos ingenios y de importantes porciones de las mejores tierras de la provincia, y el de la estructura social del agro tucumano, especialmente los concernientes a la extendida propiedad campesina y sus conexiones con los mercados de bienes y de trabajo.

Señalemos, sintéticamente, los aspectos más relevantes del proceso de gestación de la elite tucumana (a lo largo de todo el siglo xIX) considerados por los autores mencionados:

a) La diversificación de las actividades empresarias, que combinaron lá tradicional intermediación comercial entre las casas importadoras porteñas y los mercados de consumo norteños (incluyendo el altiplano boliviano), con

15 Giménez, "Interior", 1985; Balán, "Cuestión", 1978. 


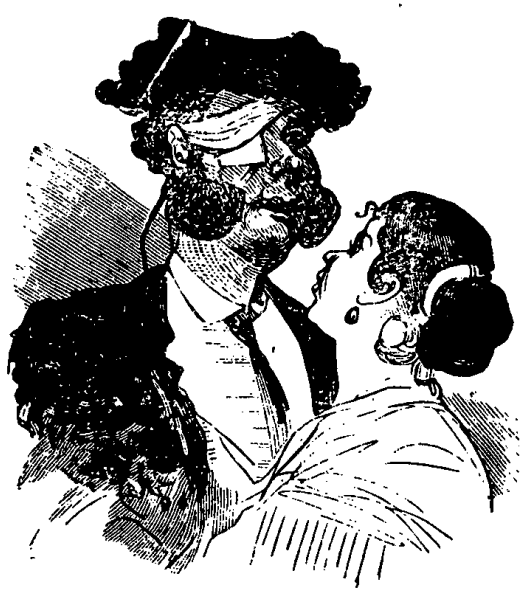

el de acopio y "exportación"16 de "frutos del país" y la intervención directa en la producción.

b) La ductilidad demostrada por el sector comercial para reinvertir en actividades agrícolas y manufactureras los excedentes acumulados en la intermediación comercial.

c) La aptitud de la elite para incorporar a lo largo del siglo elementos de diverso origen, algunos provenientes de otras provincias argentinas (catamarqueños y santiagueños, en una primera etapa; cordobeses, rosarinos y porteños durante el auge azucarero) e

${ }^{16}$ Con los términos "exportación" e "importación" se hacía referencia, en las décadas de 1850 y 1860 , al comercio de Tucumán con las restantes provincias argentinas y países limítrofies como Bolivia y Chile. Con ese sentido se los usará en este trabajo. inmigrantes europeos, dentro de los cuales se destacaron los franceses por su éxito social y económico.

d) La conjunción, en este sector social, de liberalismo político y proteccionismo económico, combinado con un gran entusiasmo por las innovaciones tecnológicas y un no menor apego a arcaicos mecanismos de dominación social (leyes represoras de la "vagancia", peonaje por deudas, papeleta de conchabo, etcétera).

g) La inextricable vinculación de negocios y política, en una ecuación en la cual estas actividades se apoyan y potencian recíprocamente.

Uno de los autores de este artículo ha hecho referencia en otro trabajo a los mecanismos de acumulación de capitales desarrollados por la elite, apoyándose en los aportes de Giménez Zapiola y Balán y en investigaciones propias. ${ }^{17}$ En el mismo se describen las actividades que permitieron a los comerciantes tucumanos convertirse, en el lapso de medio siglo, en una dinámica y audaz elite de la Argentina finisecular. Se pone de relieve, asimismo, cómo la experiencia mercantil en un amplio espacio regional se enriqueció con la adquirida en la administración de estancias y plantaciones, la gestión de ingenios, curtiembres y aserraderos, desarrollando en ese proceso una gran sensibilidad ante los indicadores del mercado para orientar (y reorientar) sus inversiones.

En ese sentido, la elite tucumana (como la mayoría de la elites de las provincias argentinas) no se corresponde con el arquetipo que sobre las clases

${ }^{17}$ Campi, "Consideraciones", 1991. 
dominantes latinoamericanas del siglo XIX proponen todavía ciertos historiadores: "la dominación oligárquica se construye a partir de la hacienda, considerada como matriz de las sociedades latinoamericanas". ${ }^{18}$ Es que la riqueza y el poder de este sector básicamente urbano no se fundaba en la hacienda (pese a que algunas de las fa. milias que la integraban hayan sido importantes propietarias de tierras y de ganado), en la percepción de rentas en trabajo o en especie, o en el sometimiento directo de la población campesina. El desarrollo en Tucumán de un importante segmento de productores independientes, que combinaban sus actividades de subsistencia con la colocación de excedentes en el mercado y/o la venta de fuerza de trabajo, la habría obligado a desarrollar otros mecanismos de apropiación del excedente campesino. Con el estudio de los circuitos comerciales locales y del papel del crédito se podrá verificar si -como lo describe Chiaramonte para Corrientes- la elite impuso su control sobre la producción agroganadera a partir del acopio de productos y las "habilitaciones" a los pequeños productores. ${ }^{19} \mathrm{El}$ pago del impuesto a las "patentes" -por parte de destacados miembros de la elite- como "compradores de cueros" y "barraqueros", apoyaría esta hipótesis. ${ }^{20}$

No conocemos todavía en detalle el tránsito de la intermediación comer-

${ }^{18}$ Ansaldi, "Frivola", 1991-1992, p. 45.

${ }^{19}$ Chiaramonte, Mercaderes, 1991.

${ }^{20}$ Archivo Histórico de Tucumán (en adelante AHT), Comprobantes de contaduría, vol. 166, ff. 574-582.

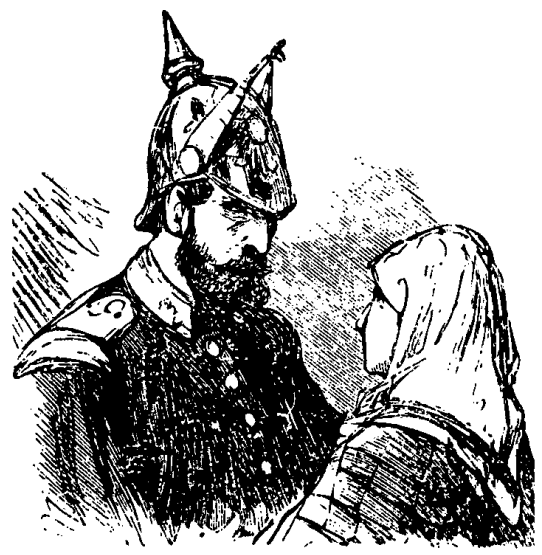

cial a la producción agroindustrial en las actividades de la elite. Junto a la difusión de las curtiembres y los aserraderos, paulatinamente se elevó el número de ingenios azucareros, que ya en 1837 sumaban 32 "en los alrededores de la ciudad capital", y 52 en $18644^{21}$ Tales "ingenios" eran, originariamente, establecimientos muy rudimentarios, con trapiches "de palo", unas pocas cuadras de caña (los más pequeños podían tener hasta dos cuadras), unos "fondos" de cobre o hierro para clarificar y concentrar los "caldos" y un elemental alambique para la producción de aguardiente.

Tres elementos, conjugados, facilitaron la difusión de estos establecimien-

${ }^{21}$ Pavoni, Noroeste, 1981, t. II, p. 10; El Liberal, Tucumán, 19 y 22 de mayo de 1864 . 
tos: la demanda de los mercados local y regional, insuficientemente abastecidos por los reputados aguardientes de uva sanjuaninos y catamarqueños; ${ }^{22}$ la reducida extensión de tierras requerida para iniciar una explotación cañera, y el relativo bajo costo de instalación de los poco sofisticados artefactos requeridos para la producción de azúcares y aguardientes (por ejemplo, en 1864 uno de estos establecimientos con todos sus elementos, una plantación de nueve cuadras de caña -18.60 hectáreas-, ubicado en las cercanías de la capital, estaba valuado en 5000 pesos bolivianos). ${ }^{23}$

Aunque existian grandes propietarios, el cuasi monopolio sobre la tierra ejercido por unas pocas familias fue desconocido en Tucumán. La gran parcelación de la propiedad, en zonas con abundante agua para riego y adyacentes al principal centro de consumo (la ciudad capital), permitió el surgimiento de un importante segmento de "cosecheros" -bastante heterogéneo por su origen, sus vinculaciones con las actividades mercantiles y su poderío económico- que tenía en funcionamiento 82

${ }^{22}$ La provincia de Tucumán era, notoriamente, la más densamente poblada de la región $y$, por consiguiente, más importante su mercado de consumo para productos no suntuarios, véase Pucci, "Población", 1992.

${ }^{23}$ El Liberal, Tucumán, 3 de julio y 17 de mayo de 1864. A principios de esa década se transfirió otro de esos establecimientos -ubicado en la banda del río Salí, también muy cerca de la capital- en 4650 pesos bolivianos. En esa época viviendas ubicadas en los alrededores de la plaza principal de San Miguel de Tucumán se vendieron en sumas que oscilaban entre 3100 y 6000 pesos bolivianos; Corizzi y Artigas, "Mercado", 1998, p. 14. ingenios en 1877, un año después de que llegara el ferrocarril a Tucumán. ${ }^{24}$

Fue la combinación de las aptitudes empresariales, los capitales acumulados y el acceso al crédito (en esto serán decisivas las vinculaciones con el poder político) lo que determinó quiénes pudieron afrontar las grandes inversiones que exigía la reconversión tecnológica, la adquisición de nuevas tierras y la ampliación de la escala de las operaciones, condiciones para permanecer en la actividad. De hecho, la gran mayoría de los "cosecheros" de la etapa "paleotécnica" de la agroindustria quedaron en el camino, 25 pero -en conjunto- es indudable que la elite supo desempeñar un dinámico papel cuando la coyuntura de la hegemonía roquista abrió posibilidades para acoplar la provincia a la expansión económica de la zona pampeana bajo el "modelo agroexportador", conexión que no era necesariamente una inevitabilidad his. tórica. En total, considerando ingenios íntegramente modernizados e importados "llave en mano", entre 1878 y 1910 se fundaron en la provincia 40 fábricas, 31 de capitales locales (de la

${ }^{24}$ La escala en que operaban la mayoria de estos ingenios era muy reducida. Schleh estima en 3000 toneladas la producción azucarera tucumana en dicho año, cifra coherente con los rendimientos culturales y fabriles usuales de la época, no más de 50 toneladas de caña por hectárea y $3 \%$, respectivamente. Schleh, Industria, 1921 , p. 281. Para 1874, J. M. Terán registró -de acuerdo con los padrones de patentes- 73 "industriales con caña azúcar" y 160 productores que cultivaban la caña para venderla "en rama", Terán, "Provincia", 1875.

${ }^{25}$ A partir de 1880 , y por varias décadas, el número de ingenios en Tucumán oscilará entre 30 y 35 . 
elite tradicional y de inmigrantes radicados), ocho de capitales extrarregionales en sociedad con empresarios tucumanos, y uno de capital británico. ${ }^{26}$ Como ha resaltado Balán, la elite local manejó totalmente la producción azucarera hasta 1880 , y luego de la irrupción del capital extrarregional no perdió más de $30 \%$ de su control. ${ }^{27}$

¿Quiénes fueron las familias que pudieron afrontar el desafío y no quebraron en la aventura? Algunas de ellas -las que más se destacaron por las innovaciones tecnológicas que se llevaron a cabo a fines de la década de 1860 y principios de la de 1870 - venían combinando desde décadas atrás las labores manufactureras con actividades comerciales de magnitud $y$, por otro lado, detentaban en gran medida el poder político. Nos referimos a los grandes comerciantes de la década de 1860 (vinculados ya a la actividad azucarera o que no tardarían en invertir en ella), propietarios de tiendas o "casas introductoras" de mercancías de importación (la firma Méndez Hnos., Vicente Gallo, Wenceslao Posse, su tío Felipe), quienes eran también "exportadores" al litoral de "frutos del país" (suelas, aperos, tabaco, quesos, etc.). Los apellidos de importantes familias "azucareras" como los Posse, los Padilla, los Nougués, los Frías, los Gallo, los Méndez, los Avellaneda, etc., aparecen en las fuentes involucrados en este tipo de "exportaciones" junto con algunos propietarios de curtiembres, como M. Berho, J. Hardoy, M. Apestey

\footnotetext{
${ }^{26}$ Pucci, "Capitales", 1988.

27 Balán, "Migraciones", 1976, p. 209.
}

y otros. En el primer grupo había quienes, asimismo, efectuaban importantes envíos de mercaderías al norte, manufacturas de cuero y "reexportaciones" de "efectos de ultramar". ${ }^{28}$ Es indudable, entonces, que el ejercicio de actividades comerciales fue sustancial en la acumulación de fuerzas que impulsó la modernización y el "despegue" azucarero que se verificó en la provincia desde principios de los setenta hasta la primera crisis de sobreproducción de 1895-1896, y que la flor y nata del empresariado azucarero de origen local que emergió en esos años se prefiguraba ya en los sesenta en el seno de la elite mercantil. ${ }^{29}$

Otro de los aspectos remarcados (la capacidad de absorber los aportes migratorios, los que en el lapso de una

${ }^{28}$ La provincia de Tucumán desempeñó en el periodo bajo estudio un papel central en la economía norteña, articulando -cual una bisagra- los mercados del litoral, los de las provincias norteñas y Bolivia, de Cuyo y el Pacífico. Era, además, la gran proveedora de suelas del litoral y de manufacturas de cuero en un amplio espacio que excedía el regional.

${ }^{29}$ Esta tesis sobre el origen comercial de los capitales locales que impuisaron el "despegue" azucarero fue fórmulada por primera vez a comienzos de la década de 1870 por Arsenio Granillo y reiterada en 1914 por el geógrafo francés Pierre Denis. En las décadas de 1970 y 1980 fue desarrollada, con variantes, por Giménez Zapiola, Donna Guy y Antonio Mitre; Granillo, Provincia, 1872; Denis, "Tucumán", 1992; Jiménez, "Interior", 1975; Guy, Politica, 1981; Mitre, Monedero, 1987. Sin embargo, independientemente de que hoy aparezca como la más coherente de las hipótesis explicativas del origen del pujante empresariado azucarero tucumano de fines del siglo XIX, está todavía pendiente una profunda investigación sobre el comercio tucumano en las décadas de 1850 y 1860 . 
generación se integraban plenamente a la elite a través de lazos familiares y económicos) merece algunas reflexiones. Estas incorporaciones no significaban un simple "engrosamiento" de la elite, sino transformaciones en su seno que refuncionalizaron sus vínculos internos y su sistema de conexiones con la sociedad global. Los inmigrantes no dejaron de aportar en este largo proceso sus vinculaciones económicas, conectando intereses y facilitando los negocios en un ámbito cada vez más amplio, lo que aparece evidente en el caso de los franceses (Nougués, Rougés, Etchecopar, Hileret, los más destacados), que rápidamente asociaron a la modernización tecnológica y expansión económica de las décadas de 1880 y 1890 a financistas y a agentes de firmas industriales de esa nacionalidad.

Pero, ¿hasta qué punto el entusiasmo por las innovaciones tecnológicas de los años sesenta y setenta y la audacia émpresaria de la elite tucumana puede atribuirse al impacto ocasionado por este aporte migratorio? No parece thábétsen esto ninguna relación causa"êfecto tol primer innovador en gran "escalla fue un empresario nativo, Baltazar Aguirre, que importó de Inglaterra, "llave en mano", un ingenio en 1859 en sociedad con el general Urquiza, a la sazón el hombre fuerte de la Confederación. ${ }^{30}$ Asimismo, quienes habían

${ }^{30}$ Justo José de Urquiza, entrerriano, fue el primer presidente constitucional argentino (1852-1858). "Confederación Argentina" era entonces el nombre oficial del país, con capital provisoria en la ciudad de Paraná, en circunstancias en que la provincia de Buenos Aires se incorporado, pocos años después, trapiches de hierro accionados hidráulicamente, eran cinco plantadores locales (tres de la familia Posse) y Evaristo Etchecopar, un vasco-francés que explotaba un trapiche desde fines de la década de 1830. En todo caso, la "sangre nueva" fortaleció el "espíritu de empresa" ya presente en la elite, que demostró ser capaz de reorientar rápidamente sus actividades y capitales a los rubros de mayor rentabilidad.

Lentamente, pero de manera sostenida, el cultivo de la caña dulce y la producción de aguardiente (más que de mieles y azúcares) demostraron ser actividades muy lucrativas, que pocos elementos de la elite desestimaron. Los años clave previos al "despegue" parecen haber sido la década de 1860 y los primeros años de la de los setenta, en la que el aumento de la productividad por la incorporación masiva de trapiches de hierro y, en menor medida, de centrífugas, evaporadores y tachos de cocimiento al vacío, redujeron drásticamente los costos y definieron la vocación azucarera del sector más dinámico de la elite tucumana. ${ }^{31}$

Aunque las tradicionales actividades comerciales, agroganaderas y manufactureras (particularmente el curtido de cueros para su exportación al litoral y la producción de quesos y pello. nes) no se abandonaban todavía y el mapa agrícola de la provincia presentaba una notable diversificación, ${ }^{32}$ la

\footnotetext{
había erigido -de hecho- en un Estado independiente (1853-1861).

${ }^{31}$ Una breve descripción de este proceso en Campi, "Consideraciones", 1991.

${ }^{32}$ León, "Desarrollo", 1993.
} 
expansión de la matrícula de peones conchabados en las dos décadas previas al "despegue" azucarero (1876/ 1880-1896) es un índice inequívoco del desarrollo de las relaciones salariales en la esfera de la producción, proceso vinculado sin duda al crecimiento del área cultivada con caña de azúcar. ${ }^{33}$

Sin embargo, como han remarcado ciertos estudios, ${ }^{34}$ el auge azucarero no significó la desaparición del importante sector de "labradores" y "criadores" que registraron los censos nacionales de 1869 y 1895 , así como los padrones de la contribución directa, los electorales y los de la Guardia Nacional del periodo. ${ }^{35}$ Éstos, pequeños productores independientes, se vincularon rápi-

\footnotetext{
${ }^{33}$ Mientras en 1864 se cultivaban unas 1400 hectáreas de caña, diez años después un informe del Departamento Nacional de Agricultura registraba casi 2 300. Los trabajadores conchabados legalmente, por su parte, se incrementaron de 4000 , en 1869, a 6750 en 1874; El Liberal, Tucumán, 19 y 22 de mayo de 1864; León, "Desarrollo", 1993, p. 227; Campi, "Captación", 1993, p. 59. Con posterioridad, en las décadas de 1880 y 1890 , la evolución de las hectáreas cultivadas con caña y de los trabajadores inscritos en los registros de conchabo se corresponden.

${ }^{34}$ Bravo, "Leyes", 1991.

35 Todavía faltan estudios para determinar el origen del minifundio tucumano. Para 1812, de acuerdo con el censo levantado ese año, en las circunscripciones de Río Chico y Los Juárez, el porcentaje de "labradores" y "criadores" sobre la población masculina con oficio era, respectivamente, de 70.1 y 27.3 y de 37.9 y 27.5 (información suministrada por María Paula Parolo). Vicente Quesada, quien visitó Tucumán en la década de 1850, recordaba: "La propiedad estaba muy subdividida; no habia grandes propietarios", Quesada, Memorias, 1942, p. 356. A su vez, en la "Memoria histórica y descriptiva" de
}

damente al crecimiento global de las actividades económicas de la provincia impulsado por la producción azucarera. Serán proveedores en pequeña escala de materia prima, de ganado para alimentar a la población flotante que en épocas de zafra se concentraban en ingenios y plantaciones, etc. Sólo el número de plantadores de caña de azúcar evolucionó de 233 a 2630 entre 1874 y $1895 .^{36}$

Esta evolución repercutirá en el seno de la elite tucumana en varios planos. Por un lado, el negocio azucarero fue la vía a través de la cual un grupo de familias multiplicaron varias veces su fortuna en muy pocos años. Por cierto, no podría ser más elocuente el contraste entre el estilo de vida de la "clase dirigente" de fines de los sesenta evocado por José Ignacio Aráoz con la magnificencia exhibida por los empresarios azucareros ya en la primera década del siglo XX. Según Aráoz, en los años previos al boom del azúcar la elite tucumana

1882 se afirma: "Uno de los principales rasgos característicos de la provincia de Tucumán, es la estrema [sic] división de la propiedad rural, no sólo en las inmediaciones de la ciudad y demás villas, sino también en todos los demás puntos de la campaña, con escepción $[s i c]$ de la serranía, y aun en esta última parte de la provincia que está casi esclusivamente [sic] dedicada a la cria de ganados, las estancias son mucho menos estensas [sic] que en la generalidad de las provincias de la república"; "Puede decirse con toda verdad que no hay en la campaña una sola familia que no sea propietaria de un pedazo de terreno y de unas cuantas cabezas de ganado vacuno o lanar que les asegure la subsistencia"; Bousquet, Memoria, 1882, pp. 501 y 441.

36 Schleh, Industria, 1921 , p. 80. 


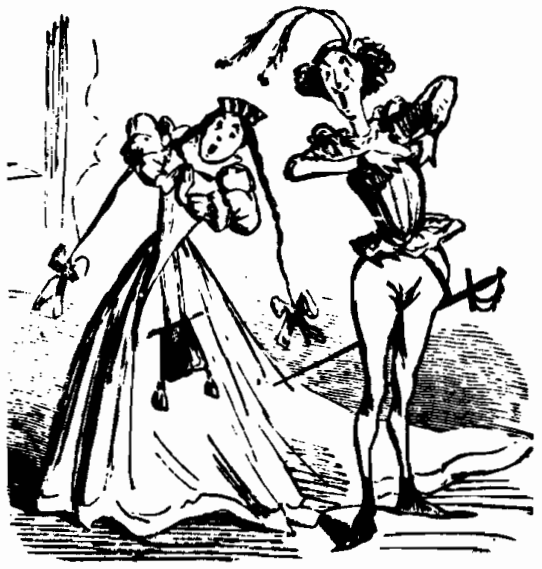

no conoció la nobleza de sangre, ni de tradición -porque era una sociedad nueva-, ni de la riqueza: pero era evidente y fuertísimo [sic] entonces un sentimiento y concepto de clase social, que se revelaba en el trato y distancia de la clase media, del peón o sirviente, y en la preocupación de las buenas relaciones [...] ¿En qué se fundaba esa alta clase social? No es fácil decirio. No había títulos ni riquezas: señoras de las principales vendian quesos, lanas y frutas en sus propias casas. Los caballeros eran tenderos, hacendados o industriales de la caña de azúcar. Niñas y señotas hacian de todo en la casa: limpieza, costura, cocina, etc. En todo caso pensaríamos que ese arraigado concepto de clase no tenía otra base que una relativa selección de descendientes de españoles y buenos extranjeros, y de un cierto grado de cultura y conducta moral, observada en una o dos generaciones, que llegaban a hacer de una persona un "decente". ${ }^{37}$

Por el contrario, los símbolos de poderío económico y prosperidad que la renovada elite azucarera despliega por toda la geografia provincial en las dos primeras décadas de este siglo impresionan por su suntuosidad. Los chalets de los ingenios, muchos rodeados de espléndidos parques que incluían lagos y plantas exóticas (diseñados por el renombrado paisajista francés Carlos Thays en el caso de los ingenios Santa Ana y San Pablo) son -junto con algunas viviendas que se erigen en la ciudad capital y una exclusiva villa veraniega, Villa Nougués- la expresión más notoria de unos años de esplendor que despertaron la admiración de ilustres visitantes y permitieron a los industriales azucareros invertir en campos en las mejores tierras de la provincia de Buenos Aires, en Santa Fe, El Chaco y Santiago del Estero, fundar entidades bancarias y vincularse a través de uniones matrimoniales con las familias más caracterizadas de la elite porteña. ${ }^{38}$

Asimismo, el proceso brindará a la elite oportunidades para utilizar las redes cimentadas en el patronazgo, en actos electorales o en golpes de fuerza. Así, en 1877, especulando sobre el resultado probable de una tensa negociación entablada entre "nacionalistas" y "unionistas", una pluma mitrista afirmaba desde La Razón:

${ }^{37}$ José Ignacio Aráoz, "Tucumán, de $\mathbf{5 0}$ años atrás. Rasgos sociales y familiares", El Orden, Tucumán, 21, 22 y 24 de enero de 1921, Il.

${ }^{38}$ Paterlini, Olga, Pueblos, 1987, pp. 113-127. 
Pero veremos la fortuna, suponiendo en unos y otros la capacidad de proceder como cuadra a los bombres de par. tido; calcularemos los cientos de ciudadanos que trabajan en los establecimientos de estos señores, y que son los que en nuestro país se llaman elementos para una elección. ${ }^{39}$

Para consignar, a continuación, el número estimado de hombres ocupados en ingenios, curtiembres y haciendas de 32 propietarios de la provincia (16 por partido). La conclusión era terminante: proclamaba la necesaria correspondencia entre la fuerza de tales redes y los resultados electorales. ${ }^{40}$

Del mismo modo, creará fuertes lazos de dependencia entre industriales y "cañeros independientes", quienes deberán pagar con fidelidad política la parte de beneficios que les tocaba como partícipes secundarios en la actividad. Pero no se trataba, estrictamente, de una simple relación coactiva. El predominio social y político de la elite se afirmaba, además, en la buena marcha del negocio azucarero, que hasta la crisis de 1895-1896 garantizó a los planta-

\footnotetext{
${ }^{39}$ La Razón, Tucumán, 7 de noviembre de 1877 (las cursivas son mías).

${ }^{40}$ Como haremos notar más adelante, en las pujas por el poder político la importancia económica de los contendientes era sólo uno de los factores en juego. Por sí misma, la movilización de peonadas no garantizaba el triunfo a ninguna facción, por más numerosos que fueran sus contingentes. En nuestro ejemplo, los "nacionalistas" (los cuales, según La Razón, agrupaban a propietarios más poderosos que sus oponentes) tuvieron que ceder los primeros puestos a los "unionistas" en la conformación de una lista única promovida por la política de "conciliación" del presidente Nicolás Avellaneda.
}

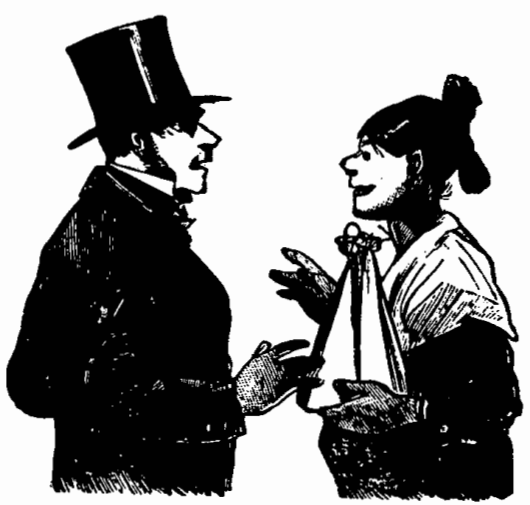

dores elevados precios por la materia prima que entregaban a los ingenios. De ese modo fortaleció su preeminencia a través del consenso, abriendo una vía de integración de los medianos propietarios y de los nacientes sectores medios urbanos al bloque de poder.

En tercer lugar, la expansión de los negocios al ámbito nacional -la "nacionalización" de la actividad como producto de la irrupción de empresarios porteños y cordobeses y la constitución de sociedades que reunían capitales de variado origen, la más importante de ellas la Compañía Azucarera Tucumana, liderada por Ernesto Tornquist- implicaba una serie de vínculos, económicos y políticos pasibles de ser volcados al ruedo local, y que incidian en las relaciones de fuerza establecidas entre facciones políticas y sectores sociales. 
Asimismo, a los ojos del naciente empresariado azucarero, el éxito de los negocios dependía en gran medida de la vigencia de políticas económicas apropiadas (protección arancelaria frente al azúcar importada, acceso al crédito de la naciente banca oficial, etc.), cuyo ámbito de resolución excedía los poderes provinciales. En consecuencia, condición necesaria del éxito empresarial era una activa participación política en la esfera nacional.

Por último -y sin que esto implique agotar las numerosas derivaciones que en el seno de la elite tucumana implicó el desarrollo azucarero-, el proceso alimentó necesariamente una moderada conciencia industrialista que se mantendría firme por lo menos hasta la tercera década del siglo $\mathrm{xx}^{41}$

Obviamente, los éxitos y fracasos empresariales, el ascenso -a veces vertiginoso-y las débâcles -a veces estrepitosas-, ocasionarán grandes transformaciones internas en su seno. Por otro lado, las alianzas y vinculaciones económicas con inversores del litoral o del extranjero y la mala o buena fortuna en las elecciones políticas a nivel nacional, también repercutirán en su estructura. ${ }^{42}$ En ese sentido, tanto la crisis

\footnotetext{
${ }^{41}$ Las rivalidades y contradicciones no resueltas entre porteños y provincianos fueron factores importantes en el proceso de alejamiento de viejas familias liberales del partido de Mitre. Sin embargo, entre las razones que incidieron en el realineamiento de casi la totalidad de la elite tucumana en torno al naciente roquismo no debe desdeñarse la mayor sensibilidad de éste a los reclamos de protección y fomento de los empresarios azucareros tucumanos.

${ }^{42}$ Frecuentemente las alianzas económicas y políticas fueron acompañadas por lazos familiares. Los Méndez, originarios del Potosí y que
}

política del 90, como la durísima experiencia de la primera crisis de sobreproducción (1895-1896) y los años de depresión que le continuaron, dejarán fuera del círculo áulico del poder y la riqueza -en un segundo plano o directamente fuera de escena- a personajes, grupos, sociedades y familias.

El panorama a fines de siglo XIX $y$ principios del $\mathrm{xx}$ se presentará complejo, cuando la actividad azucarera -como producto de la irrupción del capital extrarregional y de las crisis- se vea sometida a fuertes tensiones internas. Dentro del mismo sector industrial, los intentos de liderazgo del Grupo Tornquist serán cuestionados por los empresarios locales más fuertes e independientes (Guzmán, Hileret, Nougués, Padilla, Rougés); por otro lado,

se radicaron en Tucumán a fines del siglo Xvil, son un ejemplo paradigmático de esa vocación de la elite tucumana de vincularse a la gran política y a los grandes negocios. Muy allegados a Ernesto Tornquist, con quien Pedro G. Méndez Libarona organizó la Compañia Azucarera Tucumana a principios de los noventa, estaban también emparentados directamente con los Mitre: una hija de Ángel María Méndez y Huergo -tío carnal del anterior, constituyente, diputado nacional, director del Banco Nacional y cónsul argentino en París- habíase casado con Adolfo Mitre (hijo de Bartolomé) en 1882. Los Méndez habían modernizado el ingenio Concepción, fundado el Trinidad y el primer banco privado de Tucumán, incursionaron en la comercialización de azúcares, en negocios ferroviarios y organizaron establecimientos ganaderos en la provincia de Buenos Aires. También fueron fundadores de la Sociedad Quebrachales Chaqueños, con 600000 ha de bosques de su propiedad. A principios del siglo $\mathrm{xx}$ la familia y los negocios se radicaron en la ciudad de Buenos Aires, ocupando Pedro G. Méndez una banca en el Congreso de la Nación por esa ciudad en 1908. Méndez y Corominas, Méndez, 1991. 
en esta época comienzan a desarrollarse manifestaciones de autonomía en los medianos y pequeños productores de caña, aunque recién lograron manifestarse con plena independencia política en la década del veinte; por último, la urbanización y la irrupción de un estrato medio (comerciantes, profesionales, empleados públicos) en la capital provincial no vinculado clientelarmente con los industriales y que constituirá, años después, la base social más importante de la Unión Cívica Radical, creará problemas políticos insolubles que derivarán en la pérdida del virtual monopolio de la elite azucarera sobre los cargos electivos y el aparato estatal a partir de mediados de la segunda década del siglo. $^{43}$

\section{POLÍTICA, NEGOCIOS Y PODER}

La conformación de la elite azucarera estuvo íntimamente vinculada a la construcción del Estado y fue, en gran medida, producto de la creciente unificación económica y política del espacio nacional. El sustento de su poder económico, como se ha visto, requería de una persistente acción política ante los poderes nacionales. Del mismo modo, para acceder al agua de riego y captar a bajo costo la mano de obra era nece-

${ }^{43}$ Aunque importantes industriales azucareros (a la vez grandes propietarios de tierras), como Ramón Paz Posse y Manuel Garcia Fernández, se erigieron en prominentes figuras de la UCR, esta agrupación se caracterizó por dar cabida a numerosas líneas internas, muchas de las cuales canalizarian las aspiraciones de independencia política de las clases medias y los sectores populares. sario ejercer el mayor control posible sobre el Estado provincial. En tal sentido, el ejercicio de la política se revelaba como una actividad indisociable de los negocios, y tan modeladora como éstos de la formación social.

El ejército será clave en esta perspectiva. Como muchos hijos de caracterizadas familias del interior, algunos tucumanos encontraron en la milicia una vía de promoción política que, eventualmente, podía proyectarlos al plano nacional ${ }^{44}$ A veces, estas estrategias se pusieron al servicio del poder presidencial interesado en expandir y consolidar en todo el territorio "nacional" la autoridad vacilante del Estado central, que encontraba en las díscolas administraciones provinciales no pocos obstáculos para hacer efectivos sus propósitos y decisiones. Por ello, el ejecutivo nacional se valió de jefes militares leales (frecuentemente con sólidos lazos en el "patriciado" provinciano) para suprimir el recurrente estado de guerra interna provocado tanto por los levantamientos de las últimas "montoneras" como por los enfrentamientos entre gobernadores, que dirimían, también por las armas, sus diferencias. De

\footnotetext{
${ }^{44}$ El caso de Julio Argentino Roca es ejemplar. Pertenecía por el lado materno a la antigua familia de los Paz, integrada por militares, hacendados y doctores en leyes; el más destacado fue su tío Marcos Paz, doctor y coronel, que llegó a ser gobernador, senador nacional y vicepresidente de la república. Por el lado paterno la tradición castrense se remontaba a dos generaciones anteriores. En 1843, con motivo de su nacimiento, su padre escribió a Celedonio Gutiérrez, gobernador de Tucumán: "Anoche dio luz Agustina a un hermoso granadero. Dígnese vuestra excelencia disponer de este nuevo soldado"; Terzaga, Historia, 1976, p. 32.
} 
esa forma lograba afirmar una eficaz injerencia en los asuntos internos de las provincias, liberándose de la buena o mala voluntad de los gobernadores, quienes, paulatinamente, empezarian a obrar como "agentes naturales" del presidente. Obviamente, el telón de fondo de este proceso fueron las tensiones que generó el progresivo afianzamiento del poder central en todo el interior.

Por esos medios la autoridad presidencial y la presencia del Estado nacional se afirmó en el norte durante la gestión de Sarmiento (1868-1874). La elite tucumana secundó decididamente este propósito ayudando al sanjuanino a desmantelar el poder mitrista en la ve. cina provincia de Santiago del Estero, cuya injerencia en los asuntos tucumanos era fuente permanente de conflictos internos. ${ }^{45}$ Naturalmente, la caída de este clan santiagueño potenció el papel de Tucumán como defensor decidido de la nueva política presidencial en la región.

A fines de la década de 1860 , la poderosa familia tucumana Posse utilizó su influencia en el gobierno y en la prensa para afirmar este nuevo papel que desempeñaba la provincia en el con-

\footnotetext{
${ }^{45}$ Manuel Taboada controló la situación de Santiago del Estero durante las décadas de 1850 y 1860 y asumió como gobernador en cinco oportunidades. Su poder se consolidó durante la presidencia de Mitre, quien designó a su hermano Antonino jefe de la frontera del Chaco y de la circunscripción militar del norte, posición que le permitió intervenir e imponer su influencia en las situaciones provinciales de la región. Sarmiento advirtió con sagacidad los peligros que entrañaba semejante concentración de poderes en un gobernador que actuaba con total independencia frente al gobierno y al Congreso nacionales.
}

cierto nacional. El periódico El Nacionalista, bajo su control, proclamaba: "Levantemos nuestra bandera en dos palabras: adhesión al presidente de la República. No somos provincianos antiporteños, eso sí que no: somos argentinos." $" 46$

En esos años el "clan" ${ }^{47}$ Posse aparece representando al segmento más concentrado de comerciantes que incursionaban con manifiesta firmeza en el negocio azucarero, fundando su preeminencia política en el control que ejercían sobre extensas áreas de la provincia, tanto por su predominio económico como por el ejercicio de ciertas funciones en los departamentos del interior (jueces, comandantes de milicias, etc). Se trataba de una extensa red familiar potenciada por una vasta trama de relaciones clientelares y alianzas políticas facilitadas por la gran varie. dad de sus empresas comerciales y productivas. ${ }^{48}$

En la década de los setenta, en consonancia con el dinamismo económi-

${ }^{46}$ El Nacionalista, Tucumán, 17 de octubre de 1869.

${ }^{47}$ Se utiliza esta caracterización para designar grupos que tienen un mismo origen familiar pero en los que su estructuración excede los lazos estrictamente parentales, integrando a través de formas diversas a otras familias $e$ individuos en redes solidarias que se prolongan en vastas redes clientelares.

${ }^{48}$ Es notoria la ausencia en la historiografia argentina de trabajos sobre la Guardia Nacional y sobre el papel que desempeñó en las lides políticas. Sin embargo, no hay duda de que en Tucumán las comandancias departamentales de la Guardia, junto con las jefaturas de milicias y las comisarías de campaña, eran la representación más importante del todavía endeble aparato estatal, piezas clave para el control político del gobierno sobre toda la geografia provincial. 
co de la provincia, se verificaron fenómenos de promoción en el interior de la elite, alterando el papel de grupos y familias que hasta entonces se mantenían en un segundo plano frente al clan. Los Posse comenzaron a ver cuestionada su hegemonía. Fue su más destacado vocero, José Posse, quien en un debate en la prensa hizo una descripción minuciosa de la red familiar, de su base económica y política y de un sistema de valores con el que se pretendía legitimar el predominio político del linaje:

La familia Posse es en Tucumán una de las más antiguas y respetadas que tiene el país, y es en la actualidad la que cuenta mayor suma de riqueza acumulada. Entre los miembros de esta familia se cuentan los primeros industriales de Tucumán cuyos establecimientos representan un valor de más de un millón de duros. Además de estos grandes industriales tienen la familia Posse y sus aliados en política un considerable número de cañeros de segundo orden $[\ldots]$ en el comercio también tienen comerciantes de primer orden y fuertes capitalistas. Si desaparecieran con sus fortunas los hombres que componen la familia y el partido Posse, Tucumán quedaría en ruinas. Siempre a la vanguardia del proceso han sido los primeros en importar máquinas y adoptar procedimientos nuevos para la elaboración del azúcar y del aguardiente $[\ldots]$ dan ocupación honesta y lucrativa a millares de personas en la industria cañera $[\ldots]$ cuentan además con literatos, abogados, médicos, hombres de Estado que han figurado en la prensa, en el gobierno, en los parlamentos. He aquí lo que es y lo que cuenta el partido Posse en Tucumán. ${ }^{49}$

${ }^{49}$ La Razón, Tucumán, 7 de octubre de 1873.
La respuesta de la facción opositora al clan no cuestionó la legitimidad de los valores exaltados por los Posse. Discutía, simplemente, la exclusividad que éstos se atribuían:

Se trata de presentar a los Posse como a los únicos industriales, hacendados y comerciantes que tiene la provincia, iy los señores Méndez, Zavalia, Colombres, Frías, Gallo, Nougués, Etchecopar. Padilla, López y tantos otros? [...] No hay un solo Posse que haya sido el primero en importar máquinas, el primero en importar máquinas fue el señor Aguirre y los primeros en modificar los procedimientos han sido los señores Méndez Hermanos que enviaron a buscar hombres competentes a La Habana. Pero los señores Posse se hacen autores y dueños de todo. ${ }^{51}$

En realidad, durante las conflictivas décadas de los cincuenta y los sesenta la preeminencia del clan derivaba de su liderazgo indiscutido sobre las fuerzas liberales, de la energía con la que emprendieron sus empresas políticas, tanto para impedir que el gobernador federal Gutiérrez continuara en el poder como para enfrentar las pretensiones hegemónicas del clan santiagueño de los Taboada sobre toda la región. Como ninguna otra facción, los Posse y sus aliados expresaban el nuevo clima político antirrosista y entablaron, en consecuencia, sólidas conexiones con el liberalismo porteño. Si se suma a ello la capacidad para articular un vasto contingente de peones, labradores, artesanos y criadores, se comprende su permanente presencia en la le-

${ }^{50}$ La Razón, Tucumán, 7 de octubre de 1873. 


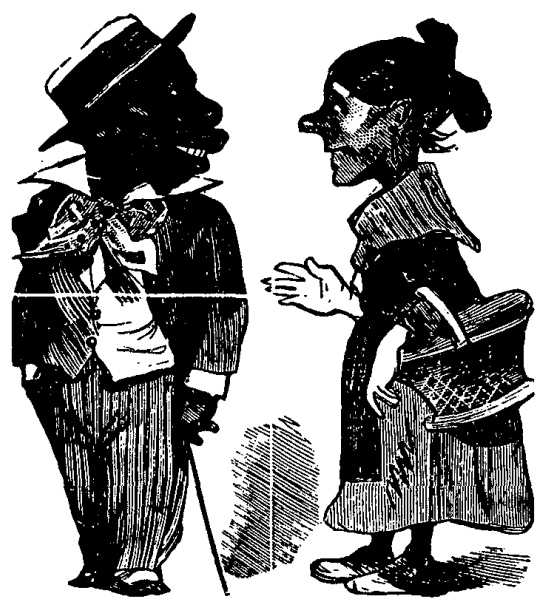

gislatura provincial, que designaba a los gobernadores.

La Constitución de 1856 fijaba en dos años la duración del cargo de gobernador y prohibía su reelección durante dos periodos consecutivos. Con esta restricción se trataba de evitar la personalización del poder político, acotar en lo posible el poder exclusivo de un clan sobre los restantes y reforzar el control del conjunto de la elite sobre el accionar del ejecutivo. El corto mandato del gobernador no interrumpía el constante clima eleccionario que renovaba la virulencia de los conflictos facciosos en los que el círculo gobernante tenia mayores posibilidades de conservar las posiciones disputadas.

La persistente defensa de la investidura presidencial sustentada por la elite tucumana -más allá de sus conflic- tos internos- se reflejó en la conquista de importantes posiciones políticas a nivel nacional. En el gabinete de Sarmiento, el ingreso de Nicolás Avellane$\mathrm{da}$-que asume la cartera de Instrucción Pública- obedecía a sus antecedentes como ministro de Gobierno de Buenos Aires durante la gestión de Adolfo Alsina más que a la influencia de su extensa familia tucumana. Sin embargo, la presencia de Uladislao Frías, ex gobernador de Tucumán, que ocupó el Ministerio del Interior en 1871, era una retribución de Sarmiento al grupo tucumano que lo apoyó en su campaña presidencial. Ésta era una posición clave por el carácter de principal "agencia de desarrollo" de ese ministerio, en tanto comprendía las funciones de obras públicas, agricultura y ganadería. ${ }^{51}$

Fue Frías quien proyectó el trazado de la línea férrea de Córdoba a Tucumán. Durante ese lapso, otras obras de menor envergadura fueron subsidiadas por el gobierno nacional: la construcción de un puente sobre el río Salí, canales de irrigación dependientes de la Municipalidad de San Miguel de Tucumán y una escuela normal. ${ }^{52}$

De esta forma, la elite tucumana se integró decididamente al esquema de poder nacional que tenía como objetivo consolidar el Estado fortaleciendo la autoridad presidencial. La arquitectura institucional, legalizada por la Constitución nacional de 1853, otorgaba mayor protagonismo a las elites provinciales por su peso en la junta de electores que designaba al presidente y por la composición del Senado, donde

\footnotetext{
St Marichal, "Políticas", 1988, pp. 95-96.

52 Guy, Política, 1981, p. 37.
} 
cada provincia tenía el mismo número de representantes. Con este sistema, las elecciones de las provincias eran decisivas para garantizar la continuidad del círculo gobernante en todas las instancias del poder. En 1873, Nicolás Avellaneda, candidato a la presidencia, escribía a Federico Helguera, gobernador saliente de Tucumán: "Acaba de llegarnos la noticia del nombramiento de López para el gobierno. Su administración ha sido útil porque ha hecho posible el nombramiento de un gobernante amigo para sucederle."\$3

Para la elite la manipulación de las elecciones era un procedimiento justificado por la manifiesta falta de autonomía del elector. Por otra parte, la representación no tenía ninguna conexión con el caudal de votantes. Durante toda la década de los setenta el promedio de sufragios en las elecciones de diputados provinciales y electores a gobernador fue -en toda la provinciade 2230 votos, aproximadamente $10 \%$ de la población masculina en condiciones de votar. ${ }^{54}$ En realidad, las elecciones eran acciones de tipo clientelar en las que participaban peones de los ingenios y fincas y población rural allegada a los grandes propietarios. Al res-

${ }^{53}$ Archivo Federico Helguera (en adelante AFH), I, carta núm. 55. Información facilitada gentilmente por Donna Guy.

${ }^{54}$ Esta información fue proporcionada por Maria José Navajas que se encuentra abocada al estudio de esta temática. Estos porcentajes se corresponden con los mencionados por Ezequiel Gallo para el ámbito nacional; Gallo, "Política", 1992, p. 57 . Un reciente estudio nos informa que, según los padrones electorales del periodo 1878-1894 que se conservan en el AHT, de un total de 4476 inscritos, 1796 (40.1\%) están registrados como "labradores" o "agricul-

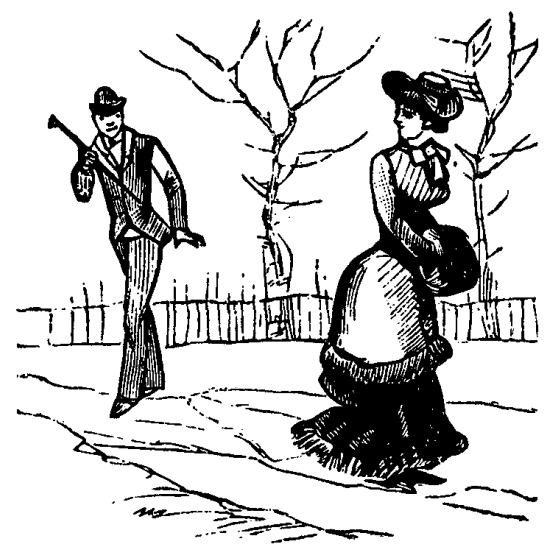

pecto, la descripción de Marco Avellaneda sobre el acto eleccionario en Tucumán es sugestiva:

traiga a su memoria el espectáculo que presentan en un día de elecciones, allí no se ve sino una chusma medio salvaje que no sabe ni el nombre del ciudadano por quien va a sufragar. Tome usted los registros electorales y encontrará por cada 100 votantes uno cuyo nombre sea conocido, o que sepa leer y escribir. $Y$ bien, éstos son los ciudadanos que hacen la elección, asistiendo a los comicios por el mandato del patrón o del comandante, o por lo menos interesados en la empanada y el aguar-

tores"; 1556 (34.8\%) como "jornaleros", y 167 (3.7\%) como "criadores". Según la misma fuente, en los dos primeros grupos, 69.7 y $92.4 \%$ de los electores, respectivamente, no sabían leer ni escribir; Viciano y Navarro "Aproximación", 1992 , p. 51. 
diente que se les propina. Si la mayoría hace la elección por la influencia que obedece, yo opino que la más legítima es la del gobierno, que es el encargado de conservar el orden público. ${ }^{55}$

Sin embargo, no hay que ver en las elecciones simples farsas que daban visos de legalidad a actos que se resolvían de antemano con el poderío económico y la capacidad de movilizar peonadas de los contendientes. En rigor, la base de la legitimidad ( $y$ en gran medida de la gobernabilidad) se fundaba, especialmente después de 1853, en el ideal de la república representativa y en el respeto de la voluntad del pueblo, aunque había bastante confusión sobre quiénes constituían el "pueblo" y, por consiguiente, una gran indefinición sobre las condiciones para acceder a la ciudadanía y sobre los propios derechos ciudadanos.

El sufragio universal regía en Santa Fe desde 1819 y en Buenos Aires desde $1821,{ }^{56}$ y se generalizó en todo el

\footnotetext{
5s AFH, I, carta núm. 20. Información facilitada gentilmente por Donna Guy.

56 Véase Bushnell, "Sufragio", 1968. Marcela Ternavasio -quien está elaborando una tesis sobre la política y las elecciones en Buenos Aires entre 1820 y 1850 - sugiere que sería más prudente llamar "sufragio amplio" al que rigió en ambas provincias desde las fechas mencionadas. De acuerdo con su punto de vista, aunque no habría dudas de que durante la década de 1820 se produjo en Buenos Aires una notable ampliación del derecho al voto, en la práctjca y en el imaginario de la época se excluían una serie de categorias sociales que no aparecen explicitadas en la ley de 1821. Por ejemplo, si la categoría de "hombre libre" definía el acceso al voto, los "dependientes" constituyen un segmento ambiguo desde el punto de vista político, ya que se discute si estaban compren-
}

territorio argentino en los cincuenta por imposición de las cláusulas constitucionales. ${ }^{57}$ Sin embargo, en las elites rioplatenses imperaba una imagen dualista de la sociedad que ponía límites difíciles de salvar para el desarrollo de un sistema de gobierno representativo de la "voluntad del pueblo". En efecto, primaba la idea de una sociedad compuesta por dos esferas, una "sana", "decente" y "civilizada" y otra "corrompida" y "bárbara". Por supuesto, el esque. ma omnicomprensivo de la realidad hispanoamericana sintetizado por Sarmiento en la oposición "civilización o barbarie" expresaba y daba sustento a dicha imagen.

No obstante, no había uniformidad de pareceres en los sectores dominan. tes sobre el trato que merecía la parte "bárbara" de la sociedad en la perspectiva de su integración en el sistema político. La polémica entre Alberdi y Sarmiento, desarrollada en 1852 al calor de los debates sobre la organización constitucional, simboliza la tensión que imperaba en la nueva arquitectura institucional y en el sistema de ideas dominantes entre los principios de exclusión e inclusión de los sectores populares. Más que matices separaban en este pun-

didos entre aquéllos. Los autores agradecen los amables comentarios de dicha investigadora sobre este punto.

57 La Constitución tucumana de 1856 establecía (siguiendo un reglamento electoral de 1826): "Son electores todos los ciudadanos argentinos que tengan veinte años de edad con exclusión de los hijos de familia y iornaleros." El Congreso nacional aprobó con revisiones el texto constitucional, dejando el requisito de la edad pero suprimiendo las restantes restricciones; Lizondo, Historia, 1948, p. 181. 
to a uno y otro. Mientras Sarmiento afirmaba:

Dícesenos que nuestros pueblos no están en estado de usar de instituciones tan perfectas. Si hubiésemos de juzgar por ciertos hechos de la República Argentina, diriamos que esos pueblos no están preparados sino para degollar, robar, haraganear, devastar y destruir. Pero hay otro orden de hechos que muestran que estos pueblos en nada ceden a los otros americanos en cuenta a su capacidad de comprender el juego de las instituciones. Ahora una constitución no es la regla de conducta pública para todos los hombres. La constitución de las masas populares son las leyes ordinarias, los jueces que las aplican y la policía de seguridad. Son las clases educadas las que necesitan una constitución que asegure las libertades de acción y de pensamiento, la prensa, la tribuna, la propiedad, etcétera. ${ }^{58}$

\section{Alberdi proponía una política más} inclusiva:

Se debe proceder a la organización social de la Argentina sin exlcuir aun a los malos, porque también forman parte de la familia. Si establecéis la exclusión de ellos, la establecéis para todos, incluso para vosotros. Toda exclusión es división y anarquía. ¿Diréis que con los malos es imposible tener libertad perfecta? Pues sabed que no hay otro remedio que tenerla imperfecta. Y en la medida que es posible el país tal cual es y no tal cual no es. Si porque es incapaz de orden constitucional una parte de nuestro pais, queremos anonadarle, mañana diréis que es mejor anonadarla toda y 37.

${ }^{58}$ Sarmiento, "Comentarios", 1895, pp. 36- traer en su lugar población de fuera acostumbrada a vivir en orden y libertad. Tal principio os llevará por la lógica a suprimir toda la nación argentina hispano colonial, incapaz de república, y a suplantarla de un golpe por una nación argentina anglorrepublicana, la única que estará exenta de caudillaje. ${ }^{59}$

La resolución de esta tensión no estuvo libre de contradicciones. Era evidente que no se podía privar de derechos electorales a los sectores populares sin violentar los principios de la soberanía popular, por lo que la Constitución consagró el sufragio universal y no estableció exclusiones fundadas en la fortuna, en identidades étnicas o religiosas para reconocer el derecho a la ciudadanía. Sin embargo, a lo largo y a lo ancho del país, no dejaron de estar vigentes antiguas instituciones de raigambre colonial que cercenaban derechos civiles a un gran segmento de la población carente de "propiedad", "renta propia" u "ocupación lícita", y a los considerados "vagos", de hecho o en potencia. Nos referimos a las leyes represoras de la "vagancia" y a la "papeleta de conchabo". A través de su aplicación se limitaba seriamente la libertad de tránsito y de trabajo a los pobres, reconociéndoseles como requisito de una existencia legal el sometimiento al tutelaje de un patrón -en el marco de una relación salarial-, en el que el Estado delegaba parte de sus potestades para "moralizar" y "civilizar" a ese sector de la sociedad. ${ }^{60}$ En consecuencia, la libertad como elector de quien esta-
59 Alberdi, Obras, 1886, pp. 16-17. 1993. 
ba sometido a estas relaciones de patronazgo era, obviamente, limitada, y -bajo el amparo de las normativas sociolaborales- muy reales las posibilidades de los patrones de manipular políticamente a sus planteles de trabajadores. ${ }^{61}$

Tales prerrogativas han contribuido a configurar una imagen de "señores feudales" que aludía a los industriales azucareros. Esta imagen sugería un poder sin límites y sin ley que ejercían indiscriminadamente en sus respectivas zonas de influencia. No es casual que durante los años de la más sangrienta dictadura militar de la historia argentina se haya afirmado -desde un punto de vista apologético de la elite-que:

En la gran mayoría de los casos, el hacer industrial se practica junto al político. Son gobernadores, ministros, legisladores nacionales. Aun en los momentos en que no tienen cargos públicos, son una suerte de jefes absolutos de la zona donde su ingenio tiene influencia: será impensable que esas circunscripciones puedan ungir legisladores o fun-

\footnotetext{
${ }^{61}$ Al respecto cabe una aclaración para no sobredimensionar estas posibilidades. No podemos dejar de considerar que las leyes de conchabo (en el caso tucumano los reglamentos de policía de 1856 y 1876 y la ley 582 de 1886), más que un reflejo del ordenamiento social eran una representación ideal de la sociedad, un instrum nto de acción sobre las relaciones sociales. un "deber ser" más que "el ser". De la documentación policial de época (en la que constan las generalizadas conductas de peones y sirvientes que transgredian reiteradamente las prescripciones de tales normativas) se desprende que las ideas que tenían los trabajadores acerca de sus obligaciones y derechos eran muy diferentes a las que aspiraba imponer la elite; véase Campi, "Auge", 1993.
}

cionarios lugareños de cualquier nivel sin su visto bueno [...] Dirimen, sin apelación, los conflictos sociales de su ámbito. No rinden cuentas a nadie y nadie se las pide. ${ }^{62}$

Aunque es indiscutible que la "voluntad del elector" no era lo decisivo en la definición de los resultados electorales, tampoco las pujas por el poder podían resolverse apelando sólo a la fuerza. En otras palabras, la conquista o el usufructo de hecho del poder no constituían fundamentos válidos del derecho a gobernar. Cada vez más, a partir de la presidencia de Sarmiento (y esto se afirma en la de Avellaneda, 1874-1880, y en la primera presidencia de Roca, 1880-1886), el respeto a las normas constitucionales constituirán la principal fuente de legitimidad del sistema, sin la cual -frente a un poder central que se asentaba en ese principio y se erigía en su custodio- las bases de la gobernabilidad se tornaban muy endebles. Por ello, los intereses privados, de círculo o facción que se encar-

${ }^{62}$ Páez, "Industrial", 1980, p. 420. Los mismos trabajos de este historiador ponen en duda el poderío sin límites que habrian detentado algunos de los clanes azucareros. Refiriéndose a los Posse, "hombres con ingenios azucareros y con estancias, al mando de peonadas que podían convertirse en ejércitos con sólo una orden", no explica cómo, habiendo movilizado a sus peones y a las milicias de La Reducción, fracasó la asonada armada con la que el clan intentó recuperar el gobierno luego de las elecciones de 1857; Páez, "Revolución", 1878, p. 69. Por otro lado, tampoco explica las razones por las que el gobierno de Juan Posse, disponiendo de una "cuantiosa parentela que sofocaba, aquí y allá, cualquier intento de revuelta", fue depuesto por las armas en 1887; Páez ,"Posse", 1972, p. 37. 
naban en redes familiares y clientelares debían conciliarse -respetando las normativas electorales vigentes- con un aceptable consenso producto de la negociación entre las diversas facciones de la elite e, igualmente, con cierto aval de los poderes nacionales, cada vez con mayores posibilidades de incidir en las situaciones locales por el desarrollo del aparato estatal y el peso creciente en las provincias de los funcionarios de los ferrocarriles nacionales, de la banca oficial, del correo, etcétera. ${ }^{63}$

En ese sentido, la legislatura, que funcionó como colegio electoral hasta la reforma constitucional de 1884 , constituía en el cónclave de la clase "principal" que dirimía, después de arduas negociaciones no exentas de tensiones y conatos de violencia, las candidaturas para gobernador. ${ }^{64}$ Obviamente se producía una constante rotación de cargos y funciones entre los representantes más destacados de las familias y facciones prominentes, aunque, como se ha señalado, algunas ganaron pro-

${ }^{63}$ No siempre era posible, sin embargo, armonizar tantos factores. Del mismo modo, a veces el poder central no actuaba como celoso garante de la legalidad frente a gobiernos provinciales adversos.

${ }^{64}$ El control de los aceitados mecanismos electorales descansaba, en gran medida, en los "gobiernos electores". Ya entonces el sistema fue descrito por Alberdi: "Los grandes electores por excelencia son los gobiernos, los candidatos serios y forzosos son esos mismos gobiernos, que se eligen y renuevan a sí mismos, directa o indirectamente [...] este hecho no es [privativo] de América, sino de todas partes y de todos los gobiernos representativos." Alberdi, Obras, 1920 , p. 66 . Esta caracterización fue retomada por Natalio Botana; Botana, Orden, 1977. tagonismo frente a otras, en un juego que se correspondía, en gran medida, con la evolución de las relaciones de poder entre los grandes agrupamientos nacionales. De ese modo, "avellanedistas" primero, y "roquistas" después, controlaron la situación frente a los enrolados en el "mitrismo".

Es en ese marco que deben estudiarse las prácticas electorales, otro ámbito casi virgen del pasado tucumano. Las elecciones otorgaban, como se ha dicho, sustento legítimo a un sistema fundado en principios republicanos; permitían, por otro lado, la resolución de los conflictos entre la elite de manera más o menos pacífica, por lo menos en un marco de legalidad; no excluían, sin embargo, el uso de la fuerza, sin la cual -de acuerdo con prácticas extendidas en todo el país- no era posible aspirar a ganar una elección; permitían, en ese sentido, proyectar al plano político el peso de las redes clientelares, las solidaridades dentro de un tronco familiar común y los lazos basados en el patronazgo; por último, posibilitaban también ampliar las bases de sustentación del sistema, incorporando paulatinamente al juego político y al bloque de poder a nuevos sectores, asimilando a los nuevos actores sociales que surgían como consecuencia del crecimiento económico, la inmigración europea, la urbanización, la escolarización y el desarrollo de las clases medias. Aunque en rigor sólo hayan formado parte del complejo mecanismo que permitía el acceso al poder, en gran medida la gobernabilidad del sistema se apoyaba en ellas: sugerían que el poder político era el genuino representante del interés general. Quizá, y 
aunque ello no respondiese estrictamente a la realidad, hacían ver que todos los varones adultos eran (o podían serlo si lo deseaban y/o luchaban por ello) ciudadanos de pleno derecho. 65

Hacia mediados de los ochenta la elite reformuló el sistema de gobierno para dotarlo de mayor estabilidad institucional. La nueva constitución de 1884 extendió el mandato de gobernador de dos a tres años, adoptó el sistema bicameral y desvinculó al poder legislativo de la elección de gobernador. En su reemplazo constituyó un colegio electoral permanente. La reforma reflejaba la consolidación del sistema de gobierno de notables y el consenso para subordinar las luchas facciosas a las prescripciones constitucionales.

El desarrollo del negocio azucarero produjo transformaciones no menos importantes en el sistema de poder. Junto al reordenamiento interno del círculo dirigente, las relaciones de pa-

\footnotetext{
${ }^{65}$ Posteriores investigaciones podrán verificar el conjunto de hipótesis propuestas en estas líneas y develar muchas interrogantes pendientes. Por ejemplo, ela participación de los sectores subalternos sólo se daba en el marco de prácticas coactivas y clientelares? Al respecto, es necesario indagar sobre la organización de "clubes" de artesanos promovidas por las diferentes facciones políticas. Al constituirse en enero de 1878, en plena campaña electoral, el Club Unión de Artesanos, que congregaba a "más de 800 artesanos de lo mejor $\mathrm{y}$ de los más respetables", el avellanedista El Independiente expresaba: "En la vida política de este pueblo es la primera vez que la clase obrera viene a reclamar y ocupar su puesto en la vida activa de la democracia para colaborar en la obra común de nuestro progreso. Una nueva era empieza y a los artesanos les corresponde el alto honor de haberla abierto [...] ellos, los primeros en el sacrificio, eran los últimos en la libertad. Siempre
}

rentesco, que continuaron siendo importantes, estarán cada vez más regidas por la lógica de las operaciones empresariales que paulatinamente se tornaron más impersonales. Por otra parte, el crecimiento del Estado desde el punto de vista administrativo y sus crecientes exigencias de profesionalización en ciertas áreas impuso un límite al accionar de los clanes.

A partir de los ochenta la elite tucumana será una elite de empresarios azucareros en la que pesarán tanto los intereses del capital como las fidelidades a un tronco familiar común. Desde 1880 se suceden gobernadores vinculados al negocio azucarero: Miguel Nougués, Santiago Gallo, Juan Posse fueron industriales; otros, como Lídoro Quinteros, que se sirvieron de su carrera política para introducirse en la actividad, también ocuparon la gobernación. ${ }^{66}$ Esta vía fue posible por el acceso al crédito, especialmente del Ban-

oprimidos, abatidos, perseguidos, llegaron, de abatimiento en abatimiento, al desencanto, esa muerte moral que hace del hombre un solitario en la sociedad, y huyeron espantados de la vida pública, donde habían agotado el sacrificio sin encontrar jamás la recompensa. De ahí esa indiferencia abrumadora por el ejercicio de esos derechos $[\ldots]$ son ellos la mayoría y por lo tanto el supremo poder." El Independiente, Tucumán, 9 de enero de 1878. Años más tarde, cuando el Partido Nacional [roquista] fomentó uniones de artesanos y obreros para potenciar su fuerza electoral, " 200 artesanos" protestaron en la prensa -a través de un manifiesto- por la caracterización de "elementos inconscientes" que se les adjudicaba desde los partidos opositores; El Orden, Tucumán, 25 de enero de 1895.

${ }^{66}$ Lídoro Quinteros luchó contra las fuerzas de Felipe Varela en 1867. Posteriormente fundó el diario La Razón, que apoyó la candidatura de Nicolás Avellaneda. En 1874 y 1880 fue elegido 


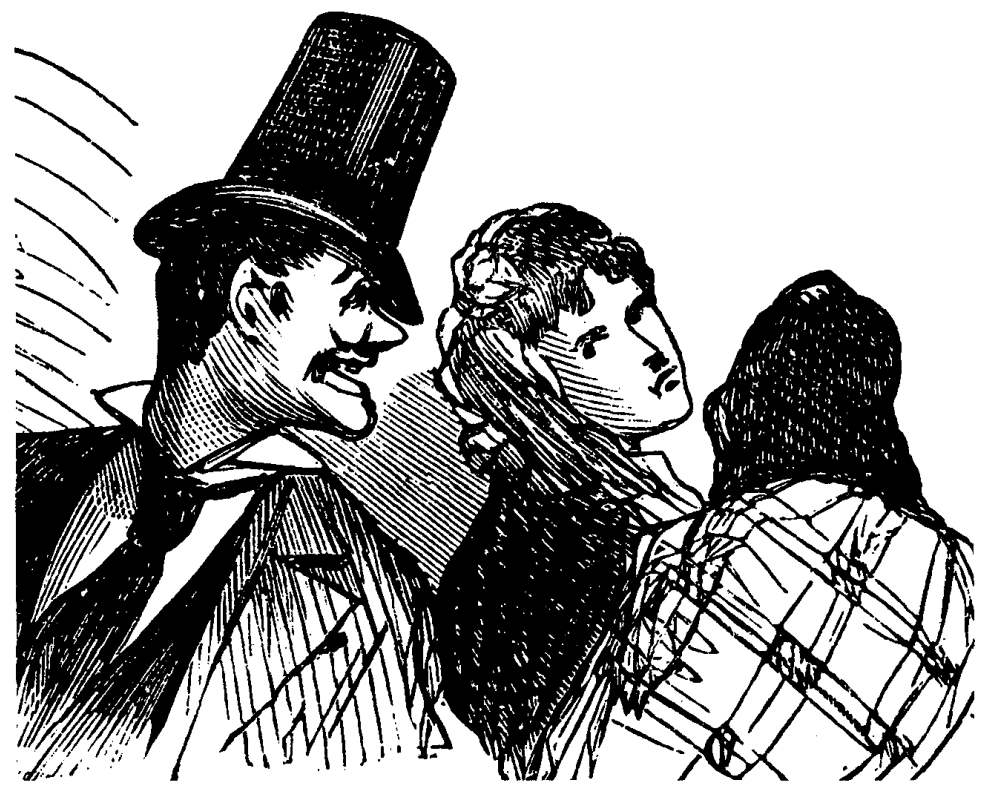

co Nacional, que a fines de 1877 instala en 'Tucumán su sucursal con capital metálico propio.

El ascenso de Roca a la presidencia significó la consolidación de un clima de unanimidad frente a las cuestiones nacionales que ya se insinuaba en la presidencia de Avellaneda. Sin duda, la organización definitiva del Estado, la ocupación efectiva del espacio nacional y la conformación de un mercado unificado, coadyuvaron a la consolida-

diputado nacional; más tarde fue gerente del Banco Nacional, del Ferrocarril Central Norte y gobernador de Tucumán. En 1896 ocupó la presidencia del Centro Azucarero. ción de la "burguesía azucarera" como sector dominante (y excluyente) en la provincia. $^{67}$

${ }^{67}$ El consenso sobre la orientación y las opciones políticas nacionales no anulaba los conflictos por cuestiones locales, intimamente vinculadas a los negocios privados. Al respecto, Nicolás Uriburu informaba a Dardo Rocha la situación del gobernador Nougués: "los círculos que apoyan hoi [sic], lo abandonan en el momento de la lucha, pues tienen tendencias y propósitos antagónicos. Todo se reduce a intereses pequeños: que quieren más aguas en las acequias de sus establecimientos, que no les multen o aprisionen a sus peones." Archivo General de la Nación (en adelante AGN), ADR, 1881, Política. 
De todos modos, una notable ruptura se produce en la conducta observada por el ejecutivo nacional frente a los gobiernos provinciales cuando asume Juárez Celman, el sucesor de Roca. En su propósito de "volcar" las "situaciones" que no le eran adictas, en 1887 suprime -mediante un golpe armadola dinámica política local, reavivando las divisiones facciosas que en las dos décadas previas habían ido perdiendo virulencia.

\section{BREVES REFLEXIONES FINALES}

El carácter de este artículo es abierto. Es decir, se trata del primer avance de una investigación sobre el sistema de poder en Tucumán en la segunda mitad del siglo XIX en el que, básicamente, se plantean una serie de interrogantes que hasta hoy no han merecido suficiente atención por parte de la historiografia regional.

Sin pretender enunciar todos los problemas atinentes a la cuestión, la resolución de los mismos deberá ser precedida por investigaciones puntuales, desde el estudio del comercio, la agricultura, la ganadería y las curtiembres tucumanas, las historias de familias, empresarios y empresas, etc., hasta las prácticas electorales -sobre las cuales mucho podría develarse integrando la información de padrones y actas con las de la prensa y la correspondencia de los actores conservada en archivos públicos y privados- y los medios de persuasión ideológicos. Del mismo modo, estudios sobre la vida cotidiana, tanto de la elite como de los sectores populares, nos permitirían acercarnos al sistema de valores y relaciones que los vinculaba y separaba.

Es indudable que hasta hoy se han formulado sólo visiones estáticas sobre la elite tucumana, las que son construcciones ideológicas más que el resultado de cuidadosas investigaciones. La documentación que hemos consultado demuestra que, por el contrario, estamos en presencia de un dinámico proceso que fue redefiniendo profundamente la composición interna de dicho sector social, destacado actor histórico pero, a la vez, "criatura" del auge azucarero. Si las circunstancias definidas por la constitución del Estado-nación y el auge agroexportador crearon las condiciones para que la burguesía comercialmanufacturera de las décadas de 1850 y 1860 evolucionara hasta transformarse en un poderoso empresariado azucarero que disfrutó del poder en condiciones privilegiadas, el mismo desarrollo económico alentó la emergencia de nuevos sectores sociales. Con la irrupción de éstos en la vida pública -en la segunda y tercera décadas del siglo $\mathrm{XX}$ su predominio político será seriamente erosionado. Pero esto forma parte ya de otra historia.

\section{ARCHIVO}

AHT Archivo Histórico de Tucumán.

AGN Archivo General de la Nación/Archivo Dardo Rocha.

HEMEROGRAFÍA

El Liberal, Tucumán.

La Razón, Tucumán.

El Nacionalista, Tucumán. 
El Independiente, Tucumán. El Orden, Tucumán.

\section{BIBLIOGRAFíA}

-Alberdi, Juan Bautista, Obras completas (Sección Cartas), Buenos Aires, 1886.

\section{La Facultad, Buenos Aires, 1920.}

-Ansaldi, Waido, "Notas sobre la formación de la burguesía argentina, 1780-1880" en Enrique Florescano (coord.), Orígenes $y$ desarrollo de la burguesia en América Latina, 1700-1955, Nueva Imagen, México, 1985.

- "Frívola y casquivana, mano de hierro en guante de seda. Una propuesta para conceptualizar el término oligarquía en América Latina", Cuadernos del CLAEH, núm. 61, 2a. serie, año $17,1991 / 2$, Montevideo.

-Balán, Jorge, "Migraciones, mano de obra y formación de un proletariado rural en Tucumán, Argentina, 1870-1914", Demografia y Economia, vol. $\mathrm{x}$, núm. 2 (29), México, 1976.

- "Una cuestión regional en la Argentina: burguesías provinciales y el mercado nacional en el desarrollo agroexportador", Desarrollo Económico, vol. 18, núm. 69,1978 , Buenos Aires.

Botana, Natalio, El orden conservador, Sudamericana, Buenos Aires, 1977.

Bousquet, Alfredo et al., Memoria bistórica y descriptiva de la Provincia de Tucumán, Buenos Aires, 1882.

Bravo, María Celia, "Las leyes machete y la ruptura del frente azucarero tucumano" en Daniel Campi (comp.), Estudios sobre la bistoria de la industria azucarera argentina, UNJu-UNT, San Salvador de Jujuy, 1991, vol. I.

-Bushnell, David, "El sufragio en Argentina y Colombia hasta 1853", Revista del Instituto de Historia del Derecbo Ricardo Levene, núm. 19, 1968, Buenos Aires.
-Campi, Daniel, "Captación y retención de mano por endeudamiento. El caso de Tucumán en la segunda mitad del siglo XIX" en Daniel Campi (comp.), Estudios sobre la bistoria de la industria azuca. rera argentina, UNJu-UNT, 1991, vol. I.

, "Consideraciones críticas sobre dos aspectos del desarrollo azucarero tucumano: acumulación de capitales y captación forzada de mano de obra", Cuadernos, Facultad de Humanidades y Ciencias Sociales-Universidad Nacional de Jujuy, núm. 2, 1991.

, "Captación forzada de mano de obra y trabajo asalariado en Tucumán, 1856-1896", Anuario IEHS, núm. 8, 1993, Tandil.

"Auge azucarero y disciplinamiento social en Tucumán en la segunda mitad del siglo XIX. La respuesta de los trabajadores", mimeo, 1993.

-Corizzi, Maria Graciela y María del Valle Artigas, "Mercado de tierras y finanzas en Tucumán, 1860-1861", Trabajo de Seminario, Facultad de Ciencias Económicas-UNT, 1998.

-Chiaramonte, José Carlos, Mercaderes del litoral, FCE, Buenos Aires, 1991.

-Denis, Pierre, "Tucumán y el azúcar" en Daniel Campi (comp.), Estudios sobre la bistoria de la industria azucarera argentina, UNJu-UNT, Tucumán, 1992 vol. II.

-Foucault, Michel, "La gubernamentabilidad" en R. Castel et al., Espacios de poder, Endymion, Madrid, 1991.

-Gallo, Ezequiel, "Política y sociedad en Argentina, 1870-1916" en Leslie Bethell (comp.), Historia de América Latina, Crítica, Barcelona, 1992, t. 10.

-García Soriano, Manuel, "El asalariado y derecho del sufragio en la legislación argentina durante el siglo XIX", Revisión Histórica, núm. 2, 1961, Tucumán.

-Giménez Zapiola, Marcos, "El interior argentino y el 'desarrollo hacia fuera': el caso de Tucumán" en Marcos Giménez Zapiola (comp.), El régimen oligárquico. 
Materiales para el estudio de la realidad argentina, Amorrortu, Buenos Aires, 1975.

-Granillo, Arsenio, Provincia de Tucumán, Tucumán, 1872.

-Guy, Donna, Política azucarera argentina. Tucumán y la generación del 80 , Fundación Banco Comercial del Norte, Tucumán, 1981.

-Halperín Donghi, Tulio, "Clase terrateniente y poder político en Buenos Aires (1820-1930)", Cuadernos de Historia Regional, Luján, 2a. etapa, núm. 15, vol. v, 1992.

-León, Carlos A., "El desarrollo agrario de Tucumán en el periodo de transición de la economía del capitalismo incipiente a la expansión azucarera", Desarrollo Económico, vol. 33, núm. 130, 1993, Buenos Aires.

-Lizondo Borda, Manuel, Historia de Tucumán. Siglo XIX, UNT, Tucumán, 1948.

-Marichal, Carlos, "Políticas de desarrollo económico y deuda externa en Argentina (1868-1880)", Siglo $X I X$, núm. 5, 1988, México.

-Méndez, Carlos Alberto (hijo) y Jorge Corominas, Los Méndez de Tucumán, Buenos Aires, 1991.

-Mitre, Antonio, El monedero de los Andes. Región económica y moneda boliviana en el siglo XLX, Hisbol, La Paz, 1987.

-Páez de la Torre, Carlos, "Los Posse de Tucumán", Todo es Historia, núm. 62, 1972, Buenos Aires.

, "La revolución de los Posse", Todo es Historia, núm. 128, 1978, Buenos Aires.

, "Un industrial azucarero: (comps.), La Argentina del ochenta al Centenario, Sudamericana, Buenos Aires, 1980.

- Tucumán, Centro Editor de América Latina, Buenos Aires, 1984.

-Paterlini de Koch, Olga, Pueblos azucareros de Tucumán, Instituto Argentino de Investigaciones de Historia de la Ar- quitectura y del Urbanismo-UNT, Tucumán, 1987.

-Pavoni, Norma, El Noroeste argentino en la época de Alejando Heredia, Fundación del Banco Comercial del Norte, Tucumán, 1981.

-Pucci, Roberto, "Capitales locales y foráneos en el auge azucarero de Tucumán (1880-1920)", 1988, mimeografiado.

, "La población y el auge azucarero en Tucumán", Breves Contribuciones del Instituto de Estudios Geográficos, Facultad de Filosofia y Letras-UNT, núm. 8, 1992, Tucumán.

-Quesada, Vicente (Víctor Gálvez), Memorias de un viejo, Solar, Buenos Aires, 1942.

-Rosenzvaig, Eduardo, Historia social de Tucumán y del azúcar, UNT, Tucumán, 1987.

-Sábato, Jorge F., La clase dominante en la Argentina moderna. Formación y características, CISEA-Grupo Editor Latinoamericano, Buenos Aires, 1988.

-Schleh, Emilio, La industria azucarera en su primer centenario, Ferrari, Buenos Aires, 1921.

-Sarmiento, Domingo Faustino, "Comentarios de la Constitución Argentina" en Obras de Domingo Faustino Sarmiento, Imprenta Mariano Moreno, Buenos Aires, 1895, tomo IV.

-Sosa, Ismael, Historia constitucional de Tucumán, Tucumán, 1945.

-Terán, Juan Manuel, "Provincia de Tucumán, 1874. Cuadro estadístico" en Informe del Departamento Nacional de Agricultura, Buenos Aires, 1875.

-Terzaga, Alfredo, Historia de Roca, Peña Lillo, Buenos Aires, 1976.

-Viciano, Carlos y R. Navarro, "Aproximación a la estructura socioprofesional en Tucumán, 1875-1895, con especial referencia a los niveles de instrucción por profesiones", Trabajo de Seminario, Facultad de Ciencias Económicas-UNT, 1992. 